\title{
Cholestasis impairs hepatic lipid storage via AMPK and CREB signaling in hepatitis $B$ virus surface protein transgenic mice
}

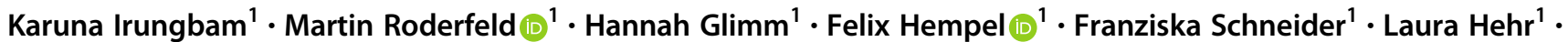 \\ Dieter Glebe ${ }^{2} \cdot$ Yuri Churin $\mathbb{D}^{1} \cdot$ Gertrud Morlock $^{3} \cdot$ Imanuel Yüce $^{3} \cdot$ Elke Roeb $^{1}$
}

Received: 27 February 2020 / Revised: 3 June 2020 / Accepted: 3 June 2020 / Published online: 1 July 2020

(c) The Author(s) 2020. This article is published with open access

\begin{abstract}
Clinical studies demonstrated that nonalcoholic steatohepatitis is associated with liver-related outcomes in chronic hepatitis B. Furthermore, primary biliary fibrosis and biliary atresia occurred in patients with HBV infection. Interestingly, hepatitis B virus surface protein (HBs) transgenic mice spontaneously develop hepatic steatosis. Our aim is to investigate the effect of $A b c b 4$ knockout-induced cholestasis on liver steatosis in HBs transgenic mice. Hybrids of HBs transgenic and Abcb4 ${ }^{-1-}$ mice were bred on the BALB/c genetic background. Lipid synthesis, storage, and catabolism as well as proteins and genes that control lipid metabolism were analyzed using HPTLC, qPCR, western blot, electrophoretic mobility shift assay (EMSA), lipid staining, and immunohistochemistry. Hepatic neutral lipid depots were increased in HBs transgenic mice and remarkably reduced in $\mathrm{Abcb}^{-1-}$ and $\mathrm{HBs} / \mathrm{Abcb}^{-/-}$mice. Similarly, HPTLC-based quantification analyses of total hepatic lipid extracts revealed a significant reduction in the amount of triacylglycerols (TAG), while the amount of free fatty acids (FFA) was increased in $\mathrm{Abcb}^{-1-}$ and $\mathrm{HBs} / \mathrm{Abcb}^{-1-}$ in comparison to wild-type and HBs mice. PLIN2, a lipid dropletassociated protein, was less expressed in $\mathrm{Abcb} 4^{-1-}$ and $\mathrm{HBs} / \mathrm{Abcb} 4^{-1-}$. The expression of genes-encoding proteins involved in TAG synthesis and de novo lipogenesis (Agpat1, Gpat1, Mgat1, Dgat1, Dgat2, Fasn, Hmgcs1, Acc1, Srebp1-c, and Ppary) was suppressed, and AMPK and CREB were activated in $\mathrm{Abcb} 4^{-/-}$and $\mathrm{HBs} / \mathrm{Abcb} 4^{-1-}$ compared to wild-type and HBs mice. Simulating cholestatic conditions in cell culture resulted in AMPK and CREB activation while FASN and PLIN2 were reduced. A concurrent inhibition of AMPK signaling revealed normal expression level of FASN and PLIN2, suggesting that activation of AMPK-CREB signaling regulates hepatic lipid metabolism, i.e. synthesis and storage, under cholestatic condition. In conclusions, in vivo and mechanistic in vitro data suggest that cholestasis reduces hepatic lipid storage via AMPK and CREB signaling. The results of the current study could be the basis for novel therapeutic strategies as NASH is a crucial factor that can aggravate chronic liver diseases.
\end{abstract}

Supplementary information The online version of this article (https:// doi.org/10.1038/s41374-020-0457-9) contains supplementary material, which is available to authorized users.

Elke Roeb

elke.roeb@innere.med.uni-giessen.de

1 Department of Gastroenterology, Justus Liebig University Giessen, Giessen, Germany

2 Institute of Medical Virology, National Reference Centre for Hepatitis B Viruses and Hepatitis D Viruses, Justus Liebig University, Giessen, Germany

3 Institute of Nutritional Science, Chair of Food Science, and TransMIT Center for Effect-Directed Analysis, Justus Liebig University Giessen, Giessen, Germany

\section{Introduction}

The injury of bile ducts is a hallmark of chronic cholestatic liver disorders of multifactorial origin leading to hepatic accumulation of bile acids (BA) and subsequent liver tissue damage $[1,2]$. Bile production is a complex process involving hepatocytes, cholangiocytes, and a number of different bile acid transporters that coordinate bile formation [1]. ATPbinding cassette subfamily $\mathrm{B}$ member 4 (ABCB4) is a phospholipid translocator at the canalicular membrane of the hepatocyte, which "flops" phosphatidylcholine into the bile. Phosphatidylcholines are essential for the formation of bile acid-containing micelles, a crucial process in protecting cholangiocyte membranes from being exposed to high concentrations of free cell-toxic BA [2]. Dysfunction or deficiency of this transporter can cause liver diseases such as 
progressive familial intrahepatic cholestasis type 3, low phospholipid-associated cholelithiasis, intrahepatic cholestasis of pregnancy, drug-induced liver injury, and chronic cholangiopathy with biliary fibrosis and cirrhosis [2]. Similar to human cholestatic liver diseases, $A b c b 4$ knockout mice develop liver fibrosis, multiple derangements of lipid metabolism, including alterations in cholesterol and phospholipid metabolism [3, 4]. Chronic viral hepatitis $(\mathrm{CVH})$ implies liver damage causing liver fibrosis and subsequent hepatocellular carcinoma formation [5]. It has been shown recently in a large combined tertiary center cohort that patients with concomitant nonalcoholic steatohepatitis (NASH) and chronic hepatitis B infection had poorer clinical outcomes [6]. Interestingly, the transgenic mice overexpressing HBV surface proteins without viral infection [7] that were used in the current study, developed hepatic steatosis [8]. Apart from steatosis, further histopathological changes have been reported in the same transgenic model including inflammation, regenerative hyperplasia, endoplasmatic reticulum stress, and associated unfolded protein response [9-11].

Characteristics of the metabolic syndrome like obesity, hypertension, and lipometabolic disorders are associated with the presence of NASH in patients with chronic hepatitis B [12]. Moreover, concurrent NASH drives a "second hit" to the liver in patients with chronic HBV infection [6] and even noninvasive score models for the prediction of NASH in patients with chronic hepatitis B and superimposed nonalcoholic fatty liver diseases (NAFLD) have been suggested [13]. NAFLD depicts the leading cause of liver diseases in the Western world [14]. Apart from HBV, also other risk factors like malnutrition, gut microbes, and drugs can aggravate NASH [15-17].

Adenosine monophosphate-activated kinase (AMPK) is believed to act as a key master switch that modulates lipid metabolism by directly phosphorylating proteins or modulating gene transcription in specific tissues such as liver, fat, and muscle [18, 19]. SREBP1c, P-ACC1, FASN, SCD1, HMGCS1, GPAT1, etc are involved either in synthesis, oxidation, or lipolysis, which are modulated directly through phosphorylation or modulation at gene transcription level by activated AMPK [19]. In addition, activation of AMPK also activates the expression of CREB [20]. The most abundant proteins associated with lipid droplets (LDs) belong to the perilipin (PLIN) protein family [21]. PLIN proteins (PLIN1-PLIN5) are important regulators of cellular lipid metabolism, directly controlling how and when cells and tissues store, mobilize, and utilize lipids. Previous studies reported on the activated AMPK-mediated phosphorylation of LD associated protein PLIN2 and subsequent triggering of lipolysis [22], suggesting an interplay between AMPK and PLIN2 in maintaining intracellular triacylglycerols (TAG) storage.

The dysregulation of hepatic and systemic lipid metabolism in $\mathrm{Abcb}^{-1-}$ mice has been described before [3].
Interestingly, the authors reported that liver injury was critically linked to impaired lipid homeostasis, which was ameliorated by norUDCA treatment and additionally by dietary intervention in $\mathrm{Abcb} 4^{-/-}$mice under HFD. Similarly, we previously reported that hepatitis B virus surface proteins could accelerate cholestatic liver injury and tumor progression in $\mathrm{Abcb}^{-/-}$mice reflecting a model of simultaneous liver damage with enhanced carcinogenesis [23]. Based on these findings, the present study was designed to investigate the effect of $A b c b 4$ knockoutinduced cholestasis on lipid metabolism in HBs transgenic mice.

\section{Material and methods}

\section{Animal experiments}

BALB/c-Abcb4 mice (C.FVB (129P2)-Abcb4 ${ }^{\text {tm1Bor }}$ herein called $\mathrm{Abcb} 4^{-1-}$ mice) were bred and housed as described previously [24]. Characterization of $\mathrm{Abcb}^{-/-}$genotype, sample collection, and routine analysis has been described elsewhere [25]. Generation and characteristics of transgenic lineages Tg (Alb1HBV) (C57BL/6J-Tg (Alb1HBV) 44Bri/ J) have been described [10]. These mice were crossed to BALB/cJ background (C.B6J-Tg (Alb1HBV) 44Bri herein called HBs mice) for nine generations. HBs mice were crossed with $\mathrm{Abcb} 4^{-1-}$ mice, resulting in the $\mathrm{F} 2$ generation BALB/c-Abcb4/Alb1HBV hybrid mice (C.Cg-Tg (Alb1HBV) 44Bri-Abcb4 ${ }^{\text {tm1Bor }}$ herein called HBs/Abcb4 $4^{-1-}$ mice). All mice were housed in a pathogen-free environment under a constant 12 -h light-dark cycle at $22{ }^{\circ} \mathrm{C}$ temperature and $50 \%$ humidity. The mice were fed standard chow (Altromin, Lage, Germany) and water ad libitum.

Mice were sacrificed at the age of $12-19$ weeks $(n=4-5$ per age and sex). Livers were collected and underwent morphological diagnosis. Remaining samples were preserved for analyses as indicated. Serum samples were stored at $-80^{\circ} \mathrm{C}$ until analysis of serum TAGs and cholesterol using the Reflotron plus Analyzer (Roche, Mannheim, Germany). This study was carried out in strict accordance to the recommendations laid in the guide for the care and use of laboratory animals of the German law of animal welfare. All experiments were approved by the committee on the ethics of animal experiments of the Regierungspraesidium Giessen, Giessen, Germany (permit number: V54-19c 2015c GI20/10 Nr. A36/2011, Nr. A5/2012, and Nr. 52_2011).

\section{Western blot}

Liver and cell lysates were prepared in $1 \times$ laemmli buffer and boiled at $95^{\circ} \mathrm{C}$ for $10 \mathrm{~min}$, and then briefly centrifuged 
Table 1 qRT-PCR primer list.

\begin{tabular}{|c|c|c|c|}
\hline Gene & Forward & Reverse & Primer bank ID \\
\hline Mtt & 5'-CTC TTG GCA GTG CTT TTT CTC T-3' & 5'-GAG CTT GTA TAG CCG CTC ATT-3' & 6678960A1 \\
\hline Plin2 & 5'-GAC CTT GTG TCC TCC GCT TAT-3' & 5'-CAA CCG CAA TTT GTG GCT C-3' & $31982516 a 1$ \\
\hline Gapdh & 5'-GGC TGT ATT CCC CTC CAT CG-3' & $5^{\prime}$-CCA GTT GGT AAC AAT GCC ATG T $-3^{\prime}$ & - \\
\hline Fasn & 5'-GGA GGT GGT GAT AGC CGG TAT-3' & 5'-TGG GTA ATC CAT AGA GCC CAG-3' & 30911099a1 \\
\hline Scd-1 & 5'-TTC TTG CGA TAC ACT CTG GTG C-3' & 5'-CGG GAT TGA ATG TTC TTG TCG T-3' & $31543675 \mathrm{a} 1$ \\
\hline Srebp-1c & 5'-GATGTGCGAACTGGACACAG-3' & 5'-CAT AGG GGG CGT CAA ACA G-3' & 27753981a1 \\
\hline$L p l$ & 5'-GGGAGTTTGGCTCCAGAGTTT-3' & 5'-TGT GTC TTC AGG GGT CCT TAG-3' & $6678710 \mathrm{a} 1$ \\
\hline Dgat1 & 5'-TCC GTC CAG GGT GGT AGT G-3' & 5'-TGA ACA AAG AAT CTT GCA GAC GA-3' & $6753632 \mathrm{a} 1$ \\
\hline Dgat2 & 5'-GCG CTA CTT CCG AGA CTA CTT-3' & $5^{\prime}$-GGG CCT TAT GCC AGG AAA CT-3' & 16975490a1 \\
\hline Acot1 & 5'-ATA CCC CCT GTG ACT AC CTG-3' & 5'-CAA ACA CTC ACT ACC CAA CTG-3' & $6753550 \mathrm{a} 1$ \\
\hline$C d 36$ & 5'-ATG GGC GT GAT CGG AAC TG-3' & 5'-GTC TTC CCA ATA AGC ATG TCT-3' & 31982474a1 \\
\hline Ppary & 5'-AGA GCC CCA TCT GTC CTC TC-3' & $5^{\prime}$-ACT GGT AGT CTG CAA AAC CAA- $3^{\prime}$ & $18875426 \mathrm{a} 1$ \\
\hline Apoe & 5'-CTG ACA GGA TGC CTA GCC G-3' & 5'-CGC AGG TAA TCC CAG AAG C-3' & $6753102 \mathrm{a} 1$ \\
\hline Vldlr & 5'-GGC AGC AGG CAA TGC AAT G-3' & 5'-GGG CTC GTC ACT CCA GTC T-3' & $15489005 \mathrm{a} 1$ \\
\hline Pctp & 5'-TTC TCG GAC GAG CAG TCC C-3' & 5'-CCG GTA GAT GGT TAT GCC TGA G-3' & $6679235 \mathrm{a} 1$ \\
\hline Apoe & 5'-CTG ACA GGA TGC CTA GCC G-3' & $5^{\prime}$-CGC AGG TAA TCC CAG AAG C-3' & $6753102 \mathrm{a} 1$ \\
\hline$M g l$ & 5'-ACC ATG CTG TGA TGC TCT CTG-3' & 5'-CAA ACG CCT CGG GGA TAA CC-3' & $12840263 \mathrm{a} 1$ \\
\hline Hsl & 5'-CCTGGCAAGCCTCATCGTC-3' & 5'-AGC AGC CCG GCT AGT AGT AG-3' & 27923943a1 \\
\hline Gpat & 5'-CAGCCAGGTTCTACGCCAAG-3' & 5'-TGA TGC TCA TGT TAT CCA CGG T-3' & 23956162a1 \\
\hline Agpat1 & 5'-TAAGATGGCCTTCTACAACGGC-3' & 5'-CCA TAC AGG TAT TTG ACG TGG AG-3' & $26352009 \mathrm{a} 1$ \\
\hline$\beta$-actin & 5'-CAG CTT CTT TGC AGC TCC TT-3' & 5'-AGT CCT TCT GAC CCA TTC CC-3' & 500747a1 \\
\hline
\end{tabular}

for $5 \mathrm{~min}$. After SDS-PAGE, proteins were transferred to a nitrocellulose membrane following the standard protocol [26]. Protein detection was performed using specific antibodies against AMPK (Genetex: \#GTX50863-100), Phospho-AMPKo (Thr172) (CST: \#2531)), Perilipin2/ PLIN2 (Proteintech: \#15294-1-AP, CIDEC: \#198204), Phospho-CREB (Ser133) (87G3) rabbit mAb (CST: \#9198), CREB (CST: \#9104), and GAPDH (Proteintech: 60004-1-Ig). The proteins were visualized using peroxidase-conjugated secondary antibodies and chemoluminescent reagent developed on Intas ECL chemostar (Göttingen, Germany). Alternatively, visualization was performed using alkaline phosphatase conjugated secondary antibodies with soluble 5-bromo-4-chloro-3-indolyl phosphate and nitroblue tetrazolium.

\section{Immunohistochemistry}

Immunohistochemistry (IHC) was performed using Impress Peroxidase/Alkaline Detection Reagents (Vector Laboratories) and antibodies specific for PLIN2 (Proteintech: \#15294-1-AP), CIDEC (Novus: NBP1-76950), lysosomal acid lipase (LAL) (Novus: NBPI-54155SS), Lipoprotein lipase (LPL) (Proteintech: \#21133-1-AP), Phospho-CREB (Ser133) (CST: \#9198), DGAT1 (Proteintech: \#11561-1AP), or MGAT1 (Santa Cruz: \#sc376079). Color reaction was developed with VECTOR VIP Peroxidase Substrate
Kit or DAB Peroxidase Substrate Kit (Vector Laboratories, USA) or HighDef ${ }^{\circledR}$ red IHC AP chromogen (Enzo, USA).

\section{Sample preparation and real-time PCR}

RNA isolation was conducted according to the manufacturer's protocol using the Direct-zol RNA extraction kit (Zymo research). cDNA synthesis was produced using the High capacity cDNA synthesis kit (Thermo, 4374966). Real-time qPCR was performed according to the protocol described before [25]. Primers were ordered from Microsynth (Switzerland). qPCR data were analyzed using the $\Delta \Delta \mathrm{C}_{\mathrm{T}}$ method [27]. Sequences and properties of primers are listed in Table 1.

\section{Oil red 0 staining}

Oil red O staining was performed as described previously [28]. Staining was assessed by bright-field microscopy.

\section{High performance thin layer chromatography (HPTLC)}

The liver tissue extracts were prepared as described [29] with slight modifications. Briefly, $20 \mathrm{mg}$ of frozen liver tissue were weighed and subsequently homogenized with $1.0 \mathrm{~mL}$ n-hexane/2-propanol 3:2 (V/V) for $1 \mathrm{~h}$. This 
suspension was centrifuged at $4{ }^{\circ} \mathrm{C}$ at $10,000 \times g$ for $10 \mathrm{~min}$. The supernatant was transferred to a vial, dried under nitrogen gas and the residue was resuspended in $100 \mu \mathrm{L}$ of chloroform/methanol 2:1 $(V / V)$. For application on the HPTLC plate, this stock solution was further diluted 1:4 in chloroform/methanol 1:1 (V/V). Individual lipid stock solutions $(25 \mathrm{mg} / \mathrm{mL})$ were mixed to obtain a lipid standard mixture of $300 \mathrm{ng} / \mu \mathrm{L}$ each in chloroform/methanol 1:1 (V/ $V$ ). The sample and standard solutions were sprayed with the Automatic TLC Sampler 4 (ATS4, CAMAG, Muttenz, Switzerland) as 8-mm bands allowing up to 21 tracks to be applied on one HPTLC plate of $20 \times 10 \mathrm{~cm}$ (distance from lower edge $8 \mathrm{~mm}$, distance from left edge $14.5 \mathrm{~mm}$, automatic distance between bands). For calibration, 0.3, 6, 12, and $21 \mu \mathrm{g}$ of the standard mixture solution were sprayed on the HPTLC plate (300-2100 ng/band) along with $2.5 \mu \mathrm{L}$ liver extract samples. After drying of the start zones for 0.5 min (hair dryer), development was performed according to [30] on an HPTLC plate silica gel $60 \mathrm{~F}_{254}$-MS-grade (Merck, Darmstadt, Germany; preheated to $110{ }^{\circ} \mathrm{C}$ for 15 min) with n-hexane/diethyl ether/acetic acid (8:2:0.4, V/VI $V$ ) in the Twin-Through chamber (CAMAG, with filter paper) pre-saturated for $20 \mathrm{~min}$. The developing distance was $65 \mathrm{~mm}$ (from the lower edge of the plate). After plate drying for $2 \mathrm{~min}$, detection was performed by immersion into primuline reagent $(100 \mathrm{mg}$ primuline in $200 \mathrm{~mL}$ acetone/water $4: 1, V / V)$ at an immersion speed of $3 \mathrm{~cm} / \mathrm{s}$ and an immersion time of $1 \mathrm{~s}$ using the TLC Chromatogram Immersion Device III (CAMAG). After plate drying for 2 min, the fluorescence measurement was performed at 366/ $>400 \mathrm{~nm}$ using the TLC scanner 4 (CAMAG, mercury lamp, measurement slit $6.0 \mathrm{~mm} \times 0.2 \mathrm{~mm}$, scanning speed $20 \mathrm{~mm} / \mathrm{s}$, optical filter K400). The chromatogram was documented at UV $366 \mathrm{~nm}$ via the TLC Visualizer (CAMAG). All instrumentation and data processing were operated with the winCATS software (CAMAG, version 1.4.6.2002).

For qualitative visualization, HPTLC plates were derivatized using sulfuric acid-anisaldehyde reagent $(201 \mathrm{~mL}$ sulfuric acid/acetic acid/methanol/anisaldehyde, 1:2:17:0.1, $V / V / V / V)$. The plate was immersed into the derivatization reagent at a speed of $3.5 \mathrm{~cm} / \mathrm{s}$ and a time of $1 \mathrm{~s}$, followed by heating at $110^{\circ} \mathrm{C}$ for $9 \mathrm{~min}$. The chromatograms were subsequently documented at white light illumination.

The selected zones were online transferred with methanol (flow rate $0.1 \mathrm{~mL} / \mathrm{min}$ ) using the TLC-MS Interface 2 (equipped with an elution head, $4 \times 2 \mathrm{~mm}, \mathrm{CAMAG}$ ) coupled to the Q Exactive Plus Hybrid Quadrupole-Orbitrap Mass Spectrometer (Thermo Fisher Scientific). Between the interface and the mass spectrometer, a filter frit (Upchurch Scientific A-356 and PEEK-Frit Blue UPA-703, Techlab, Erkerode, Germany) was installed to prevent the mass spectrometer from particles. As ion source was used atmospheric pressure chemical ionization. The spectrometer was operated and spectra were recorded with Xcalibur 3.0.63 software (Thermo Fisher Scientific). High-resolution mass spectra were measured as full scan at a resolution of 280,000 in the range of $\mathrm{m} / \mathrm{z} 100-1000$.

\section{Electrophoretic mobility shift assay (EMSA)}

The target oligo's probe sequence for CREB consensus binding site was provided by Santa Cruz Biotechnology, Inc. (sc-2504). CREB consensus sequences (F) 5'-AGA GAT TGC CTG ACG TCA GAG AGC TG-3'(R) 5'-CTA GCT CTC TGA CGT CAG GCA ATC TCT-3'. PPAR consensus binding sequences: (F) 5'-CAA AAC TG GTC AAA GGT CA-3', (R) $5^{\prime}$-TGA CCT TTG ACC TG TTT TG- $3^{\prime}$. The $5^{\prime}$ ends of all single-stranded probes were biotin labeled. Nonbiotin-labeled probes were also used as competitor probe (Microsynth, Germany).

Nuclear proteins extraction from liver samples was performed using NE-PER ${ }^{\mathrm{TM}}$ Nuclear and Cytoplasmic Extraction Reagents (Thermo scientific, cat no. 78833). For the EMSA reaction, $2 \mu \mathrm{g}$ of the nuclear protein was incubated with reaction reagents as per the protocol given in Light shift Chemiluminescent EMSA Kit (Thermo Scientific, cat no 20148). After a $10 \mathrm{~min}$ equilibration to $25^{\circ} \mathrm{C}$, biotin labeled (hot probe) and excess of nonbiotin probes (cold probe) were added and further incubated for 20-30 min at room temperature. After hybridization, the complexes were resolved by electrophoresis on $5 \%$ nondenaturing polyacrylamide gels in $0.5 \times \mathrm{TBE}$ (Tris-borateEDTA) buffer at $10 \mathrm{~V} / \mathrm{cm}$ for $1 \mathrm{~h}$. The gel was subsequently transferred to a positively charged nylon membrane using a semidry transfer cell. DNA was detected using Light shift Chemiluminescent EMSA Kit (cat no 20148, Thermo Scientific). Images were processed by Intas Imager (ECL chemostar, Intas, Germany).

\section{Lipase activity assay}

Liver samples were weighed and lysates prepared in PBS plus protease inhibitor in cold condition as per protocol (Cayman cat no. 700640).

\section{Free fatty acid (FFA) quantification}

Liver samples were weighed and lysates were prepared as per protocol for FFA quantification (Promokine, cat no. PKCA577-K612).

\section{TAG colorimetric assay}

Liver samples were weighed and lysates prepared as recommended by the manufacturer (Cayman, cat no. 

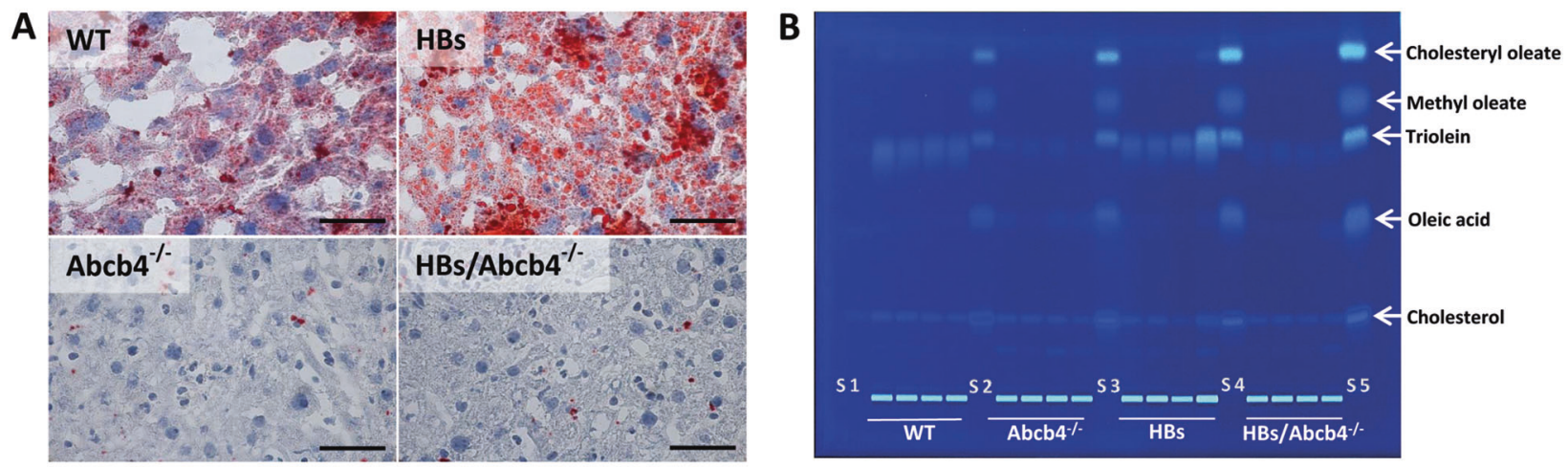

C

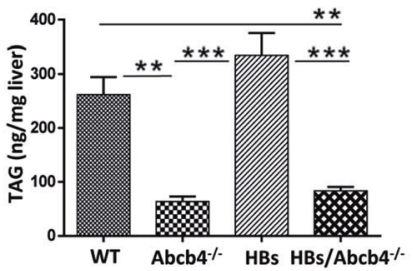

$\mathbf{F}$

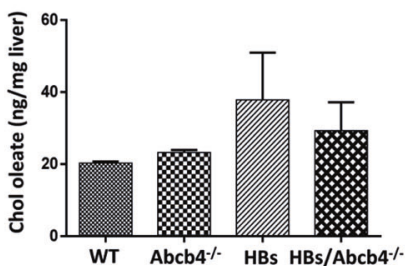

D

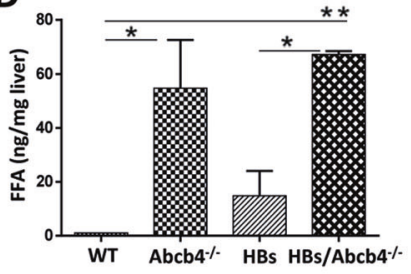

G

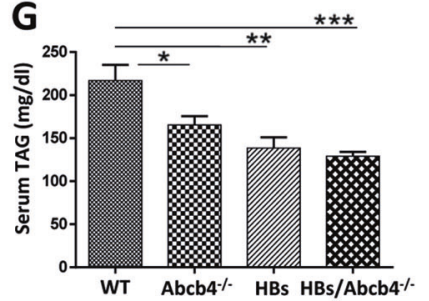

E

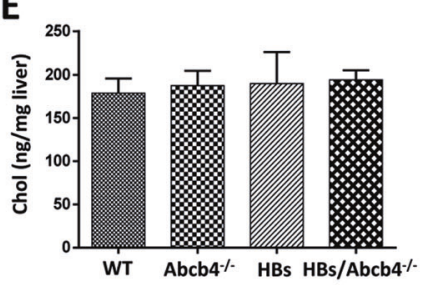

H

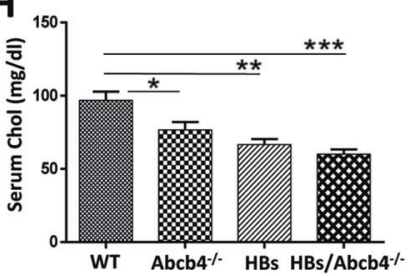

Fig. 1 Reduced lipid accumulation in $\mathbf{H B s} / \mathrm{Abcb4}^{-1-}$ mice. a Representative Oil red $\mathrm{O}$ staining demonstrated decreased accumulation of neutral lipids in $\mathrm{Abcb} 4^{-1-}$ and $\mathrm{HBs} / \mathrm{Abcb}^{-/-}$in comparison to WT and HBs mice (original image magnification $\times 1000$, bar $50 \mu \mathrm{m}$ ). $\mathbf{b}$ Representative HPTLC-FLD chromatogram at $366 \mathrm{~nm}$ of the nonpolar lipids after AMD2 separation and derivatization with the primuline reagent. c-f Mean content of TAGs (triolein equivalents), cholesterol,

10010303). The assay was initiated with the enzymatic hydrolysis of the TAGs by lipase to produce glycerol and FFAs. The glycerol released was subsequently measured by a coupled enzymatic reaction system with a colorimetric readout at $540 \mathrm{~nm}$.

\section{HepG2 cell culture}

HepG2 cell lines were obtained from CLS services Germany. HepG2 cells were grown at $37^{\circ} \mathrm{C}$ in an atmosphere of $5 \% \mathrm{CO}_{2}, 95 \%$ air in cell culture dish using $10 \mathrm{~mL}$ of DMEM-F-12 medium with $10 \%$ fetal calf serum, $1 \%$ penicillin, $1 \%$ streptomycin, and $1 \%$ fungizone. Cells were plated at a split ratio of 1:4. The preconfluent cells were left either untreated (control cells) or pretreated with oleic acid (BSA conjugated oleic acid, Sigma cat no. O3008-5ML), at a concentration of $250 \mu \mathrm{M}$ for $12 \mathrm{~h}$. Subsequent treatment with BA (Sigma-Aldrich, cat no. 48305-50G-F) was performed in serum free DMEM-F-12
FFAs (oleic acid equivalents), and cholesteryl oleate in the liver extracts determined after densitometric fluorescence measurement at $366 />400 \mathrm{~nm}$. The results represent the mean \pm SEM from at least two independent HPTLC plates with four independent liver extracts $(n=4$, $2 \sigma^{\star}+2 \%$, age 16-19 weeks) in each group. $\mathbf{g}$, $\mathbf{h}$ Serum TAGs and cholesterol estimation using Reflotron kit with $n=10(5 \hat{\jmath}+5$, age 16-19 weeks) in each per group. $* P<0.05, * * P<0.01, * * * P<0.001$.

medium. Similarly, for inhibitor assays, the cells were pretreated with Dorsomorphin (AMPK inhibitor, Merck, P5499, $10 \mu \mathrm{M}$ ) for $1 \mathrm{~h}$ prior to treatment with the BA. The plasmid $\mathrm{pCH} 9 / 200 \mathrm{LMS}$ is a replication-defective variant of plasmid pCH9/3091 [31] and encodes the HBV surface proteins under their natural promoters. HepG2 cells with $80 \%$ confluence were transfected with and without the plasmid pCH9/200LMS for $48 \mathrm{~h}$, followed by treatment with oleic acid for $12 \mathrm{~h}$. After that treated with bile acid in serum free DMEM for the next $24 \mathrm{~h}$.

\section{Statistics}

The results are presented as means \pm SEM. One-way ANOVA followed by Tukey's multiple comparisons test was performed using GraphPad Prism version 7.00 for Windows, GraphPad Software, La Jolla, CA, USA, and controlled with SPSS26.0, IBM, Ehningen, Germany. 

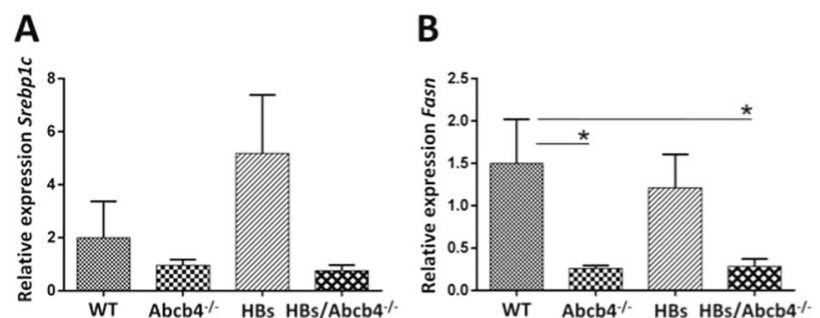

$\mathbf{F}$
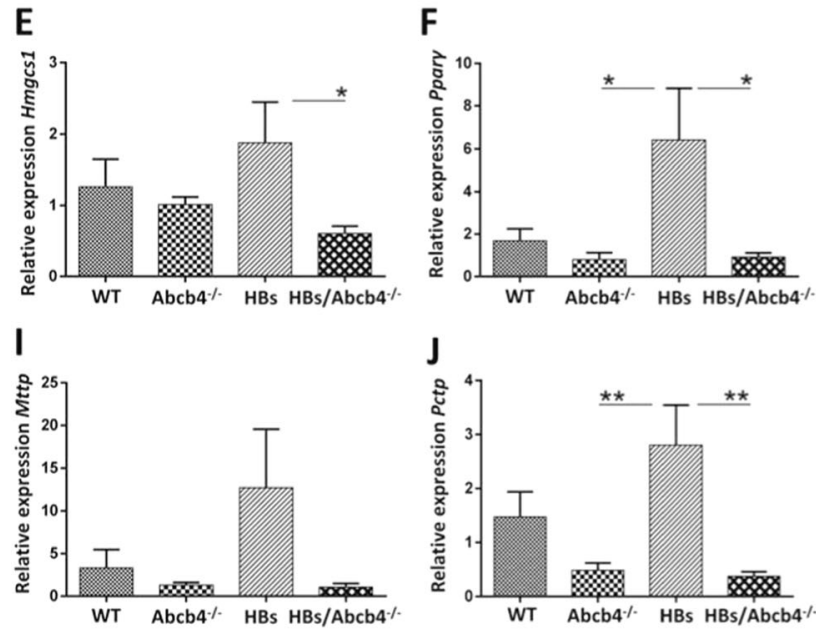

Fig. 2 Alteration of hepatic lipid metabolism in $\mathbf{H B s} / \mathbf{A b c b 4}^{-1-}$ mice. $\mathbf{a}-\mathbf{j}$ Relative mRNA expression of major genes involved in de novo lipogenesis, SREBP-1c, FASN, ACC1, Scd1, Hmgcs1, PPAR $\gamma$, CD36, ApoE, MTTP, and PCTP in livers of four different groups, normalized against $\beta$-actin gene. Housekeeping genes and primers used are listed in Table 1. Total RNA was isolated, cDNA synthesized

\section{Results}

\section{Abcb4 knockout reduced hepatic lipid accumulation in HBs transgenic mice}

We investigated the effects of $\mathrm{Abcb} 4^{-1-}$-induced cholestasis in two distinct models, Abcb4-deficient mice $\left(\mathrm{Abcb}^{-/-}\right)$and HBs overexpressing mice as well as chimera of both, knockout and transgene, on $\mathrm{BALB} / \mathrm{c}$ genetic background (HBs, HBs/Abcb4 ${ }^{-l-}$ ). Oil red $\mathrm{O}$ staining revealed a remarkable reduction of neutral lipid depots in the hepatocytes of both, Abcb4 $4^{-1-}$ and HBs/Abcb4 ${ }^{-/-}$, mice in comparison to wild-type and HBs transgenic mice, respectively, (Fig. 1a).

An HPTLC method with fluorescence detection after derivatization with the primuline reagent (HPTLC-FLD) allowed the separation and detection of five different lipid species (cholesterol, FFAs with oleic acid as reference, TAG, methyl oleate, and cholesteryl oleate) in liver extract samples. The lipid fractions were assigned using a lipid standard mixture (Fig. 1b). These preliminary assignments were confirmed by high-resolution mass spectrometry (Supplementary Fig. 1a-d). The HPTLCFLD chromatogram and its quantitative analysis revealed $0.05, * * P<0.01$.
C

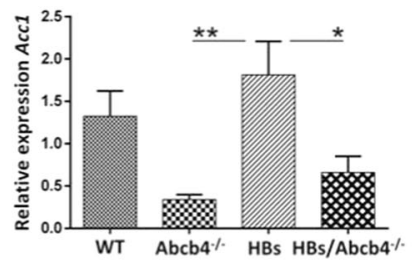

D
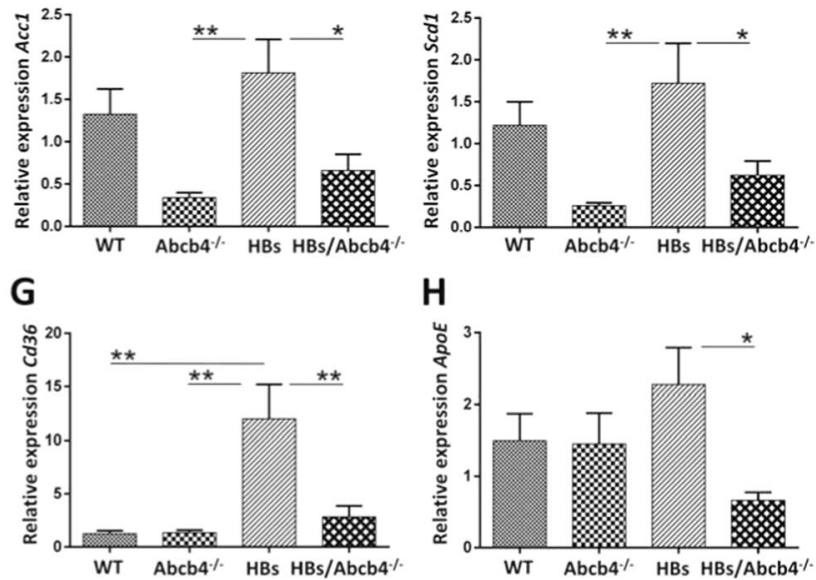

and relative quantitation was performed in applied biosystem step one real-time PCR system (Bio-Rad). Individual fold changes relative to WT were calculated and presented as mean \pm SEM, $n=7-10\left(3-5 \sigma^{+}+\right.$ 4-5ㅇ, age 16-19 weeks) in each group performed in duplicates. $* P<$

a decrease in hepatic TAGs in Abcb4 $4^{-1-}$ mice as compared to wild type (Fig. 1c). HBs mice presented with higher hepatic TAG levels than $\mathrm{Abcb} 4^{-/-}$mice, which were reduced in $\mathrm{HBs} / \mathrm{Abcb} 4^{-/-}$(Fig. 1c). The hepatic levels of FFA, on the other hand, were significantly increased in Abcb4-deficient mice and $\mathrm{HBs} / \mathrm{Abcb}^{-1-}$ in comparison to wild-type and $\mathrm{HBs}$ mice, respectively (Fig. 1d). The amount of hepatic cholesterol and cholesteryl oleate was not altered among groups (Fig. 1e, f). Alternative HPTLC assessments of TAGs and FFAs strengthened this outcome and displayed comparable results (Supplementary Fig. 1a, b).

Serum levels of TAGs and cholesterol were reduced in all groups in comparison to WT but not altered in HBs/ Abcb4 $4^{-1-}$ mice compared to $\mathrm{HBs}$ and $\mathrm{Abcb} 4^{-/-}$mice, respectively, (Fig. 1g, h). Taken together, TAGs were reduced in liver but not in the serum of HBs/Abcb4 ${ }^{-1-}$ compared to HBs mice.

\section{Abcb4 knockout altered hepatic lipid metabolism in HBs/Abcb4 ${ }^{-1-}$ mice}

The reduction of TAGs in hepatocytes of HBs/Abcb4 $4^{-1-}$ mice in comparison to HBs mice prompted us to investigate 


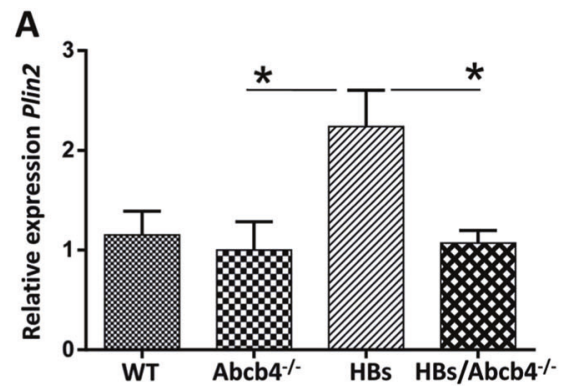

C

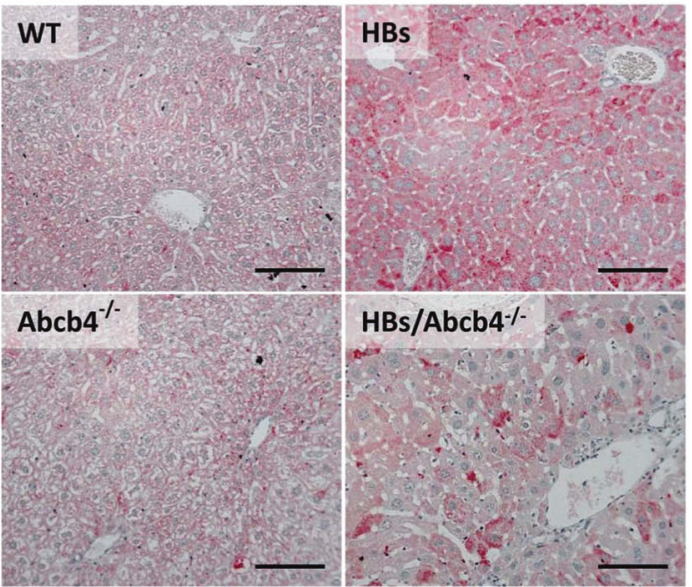

Fig. 3 Reduced expression of LDs associated protein, PLIN2 in HBs/Abcb4 ${ }^{-I-}$ mice. a Graph representing hepatic mRNA expression of PLIN2 gene relative to gene expression in WT of four different mice groups, normalized against GAPDH gene. $n=7-10(3-5 \hat{\jmath}+4-5$ 우 age $16-19$ weeks), $* P<0.05$. b Representative western blot analysis demonstrated reduced levels of PLIN2 and CIDEC in liver lysates of

the genes involved in de novo lipogenesis, lipid uptake, and transport.

Although Srebp-1c appeared increased in $\mathrm{HBs}$ and reduced in $\mathrm{HBs} / \mathrm{Abcb}^{-1-}$ by trend, statistical significance was not reached and the expression of Srebp-1c was not altered in $\mathrm{Abcb}^{-1-}$, $\mathrm{HBs}$, and $\mathrm{HBs} / \mathrm{Abcb}^{-1-}$ mice in comparison to wild type (Fig. 2a).

Fatty acid synthase (Fasn) gene expression was reduced in $\mathrm{Abcb}^{-1-}$ and $\mathrm{HBs} / \mathrm{Abcb}^{-1-}$ compared to wild type (Fig. 2b). Accl and Scdl were reduced in $\mathrm{Abcb}^{-1-}$ and $\mathrm{HBs} / \mathrm{Abcb}^{-/-}$compared to HBs mice (Fig. 2c, d). Hmgcsl was reduced in $\mathrm{HBs} / \mathrm{Abcb}^{-1-}$ compared to $\mathrm{HBs}^{-}$ mice (Fig. 2e). The transcription factor Ppary was downregulated in $\mathrm{Abcb}^{-1-}$ and $\mathrm{HBs} / \mathrm{Abcb} 4^{-/-}$mice compared to HBs (Fig. 2f).

Furthermore, $C d 36$ (fatty acid translocase) was induced in HBs compared to WT and reduced in $\mathrm{Abcb} 4^{-1-}$ and HBs/ $\mathrm{Abcb} 4^{-1-}$ mice compared to HBs (Fig. 2g). ApoE was reduced in HBs/Abcb4 ${ }^{-1-}$ mice compared to HBs (Fig. 2h). Although Mttp appeared increased in HBs and reduced in $\mathrm{HBs} / \mathrm{Abcb}^{-1-}$ by trend, statistical significance was not reached and Mttp (Microsomal TAG transfer protein) was not altered (Fig. 2i).
Abcb4 ${ }^{-/-}$and HBs/Abcb4 $4^{-1-}$ in comparison to WT and HBs transgenic in male mice. Equal loading was confirmed by GAPDH analysis. c Representative immunohistochemical analysis of PLIN2 depicts decreased expression in $\mathrm{Abcb} 4^{-l-}$ and $\mathrm{HBs} / \mathrm{Abcb} 4^{-1-}$ in comparison to WT and HBs transgenic male mice. Original image magnification $\times 200$, bar $100 \mu \mathrm{m}$.

Phosphatidylcholine transfer protein (Pctp), responsible for transfer of phosphatidylcholine, was reduced in $\mathrm{Abcb}^{-1-}$ and HBs/Abcb4 ${ }^{-1-}$ compared to HBs (Fig. 2j).

Taken together, our results indicate that $A b c b 4$ knockout suppressed the expression of genes involved in de novo lipogenesis as well as transcription factors and genes involved in lipid transport in $\mathrm{HBs} / \mathrm{Abcb}^{-1-}$ mice.

\section{Abcb4 knockout reduced hepatic lipid droplet- associated protein PLIN2, TAG synthesis, and TAG storage in $\mathrm{HBs}$ mice}

Among PLIN proteins, PLIN2 is the constitutive and ubiquitously expressed protein that has been used as a marker for LDs, correlating with the amount of LDs and TAG storage [32]. We therefore investigated the effect of an $A b c b 4$ knockout on the PLIN2 expression as an additional marker for intracellular lipid storage. Real-time PCR, western blot, and IHC revealed a reduced expression of PLIN2 in $\mathrm{HBs} / \mathrm{Abcb}^{-1-}$ compared to $\mathrm{HBs}$ transgenic mice (Fig. 3a-c). Western blotting analyses suggested a similar reduction of hepatic PLIN2 in female mice (Supplementary 
A

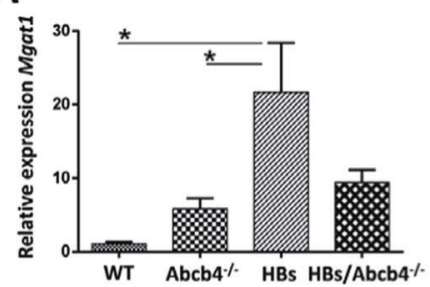

D

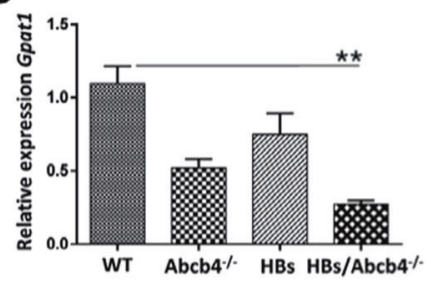

B

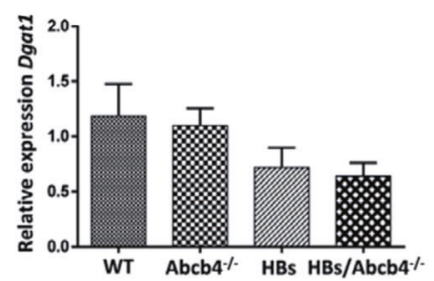

E

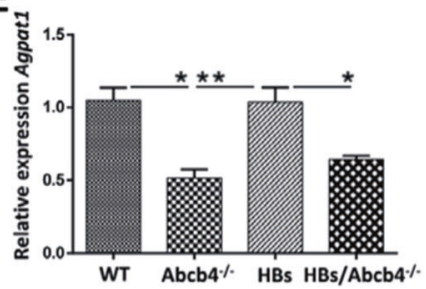

C

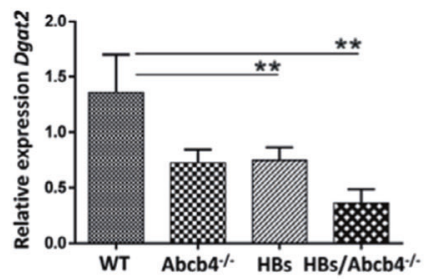

$\mathbf{F}$

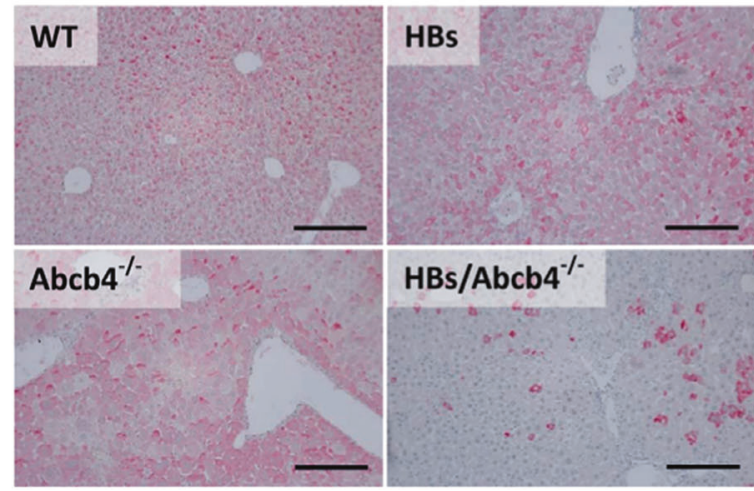

Fig. 4 Reduced TAG synthesis and storage in $\mathrm{HBs} / \mathrm{Abcb4}^{-I-}$ mice. a-e Graph representing mRNA expression of major genes involved in triacylglycerol synthesis; MGAT1, DGAT1, DGAT2, GPAT1, and AGPAT1 in the liver of four different groups, relative to WT and normalized against $\beta$-actin gene. The primers used are listed in Table 1. Total RNA was isolated, cDNA synthesized and relative quantitation was performed in applied biosystem step one real-time PCR system. The results are presented as mean \pm SEM, $n=7-10$

Fig. 2a, b). Plin2 is stained red. The protein expression of PLIN3 and PLIN5, however, was not regulated (data not shown). CIDEC, another LD-associated protein, showed a remarkable reduction in protein expression in $\mathrm{Abcb} 4^{-1-}$ and $\mathrm{HBs} / \mathrm{Abcb}^{-1-}$ mice compared to wild-type and HBs transgenic mice (Fig. 3b). In conclusion, the reduction of PLIN2 might be considered as an indicator of reduced TAG storage in consequence of the $A b c b 4$ knockout.

Thus, we further investigated genes mainly involved in TAG synthesis pathways. Transcription of Mgatlwas highly upregulated by HBs (Fig. 4a). Diacylglycerol acyltransferase 1 (DGAT1) and DGAT2 both catalyze the final committed step of TAG synthesis. At transcriptional level, Dgat2 was downregulated in $\mathrm{HBs}$ and $\mathrm{HBs} / \mathrm{Abcb}^{-1-}$ as compared to WT, while Dgat1 showed no significant regulation (Fig. 4b, c). Similarly, acyl-CoA: glycerol-3phosphate acyltransferase (GPAT) and acyl-CoA: 1-acyl-

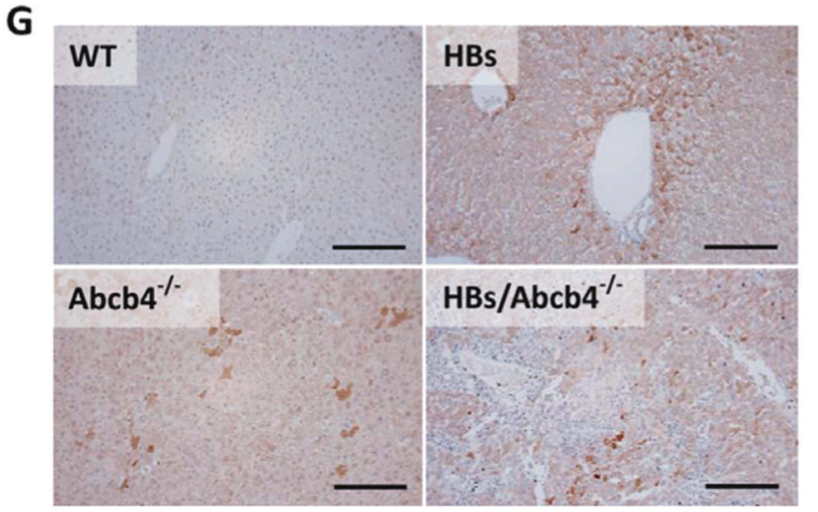

(3-5ð $+4-5$ \%, age 16-19 weeks) in each group performed in duplicates. $* P<0.05, * * P<0.01$. f Representative immunohistochemical staining using specific antibodies against DGAT1 was performed with male mice (original image magnification $\times 200$, bar $200 \mu \mathrm{m}$ ). $\mathbf{g}$ Representative immunohistochemical staining using specific antibodies against MGAT1 in male mice. Original image magnification $\times 200$, bar $200 \mu \mathrm{m}$.

glycerol-3-phosphate acyltransferase (AGPAT) are involved in the de novo synthesis of TAGs in the glycerol3-phosphate pathway. Our results displayed a downregulation of Gpat1 in $\mathrm{HBs} / \mathrm{Abcb} 4^{-1-}$ mice in comparison to WT but only in tendency in comparison to $\mathrm{HBs}(P=$ 0.081). Agpatl was reduced at transcriptional level in both, Abcb4 ${ }^{-1-}$ and $\mathrm{HBs} / \mathrm{Abcb} 4^{-1-}$ mice, compared to wild-type and HBs mice (Fig. 4d, e). Taken together our findings suggest that the reduction of TAG synthesis is associated with the reduction of LDs and LD-associated proteins in Abcb4-deficient HBs mice. DGAT1 protein expression, however, showed a remarkable reduction in $\mathrm{HBs} / \mathrm{Abcb} 4^{-1-}$ in comparison to $\mathrm{Abcb} 4^{-1-}$ and HBs mice (Fig. 4f). The protein expression of MGAT1, which synthesizes DAGs by catalyzing the acylation of monoacylglycerols (MAGs), showed a slight reduction in $\mathrm{HBs} / \mathrm{Abcb} 4^{-1-}$ compared to HBs (Fig. 4g). 
A

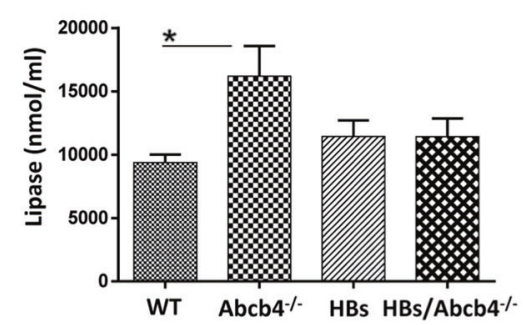

B

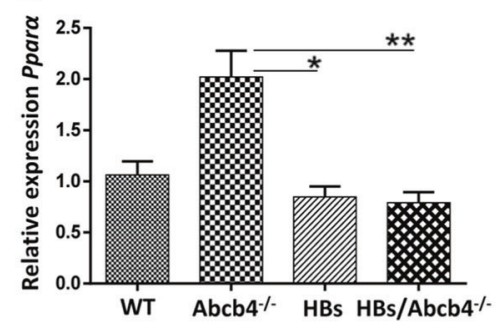

D

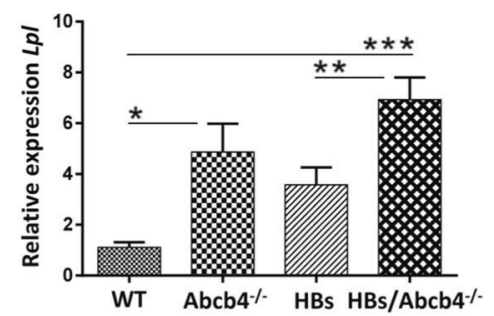

C

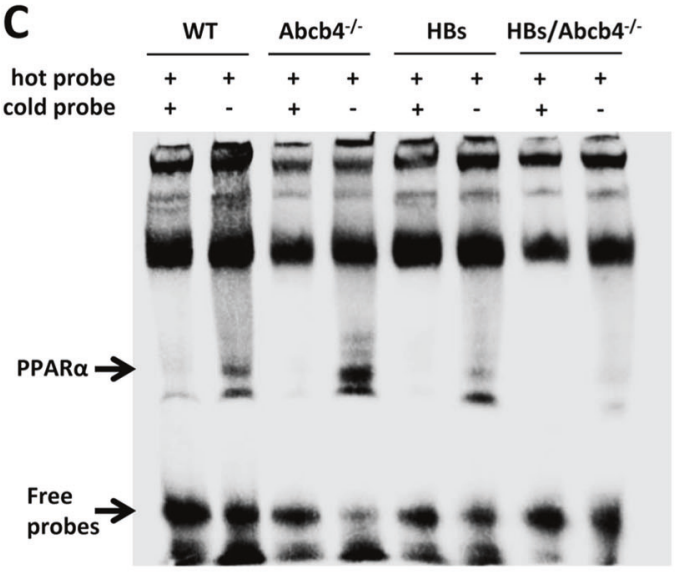

$\mathbf{E}$

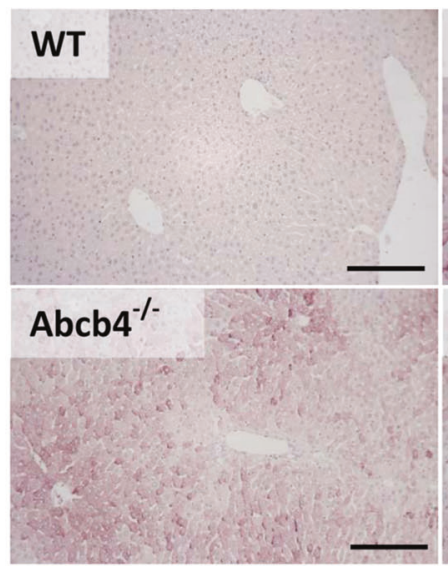

HBs

Fig. 5 Enhanced lipolysis in $\mathbf{H B s} / \mathbf{A b c b 4}^{-/-}$mice. a Total lipase activity assay was performed using liver lysate prepared as per the protocol given in Cayman lipase assay kit (Cat. No. 700640), $n=6$ $\left(3 \sigma^{*}+3\right.$, age 16-19 weeks). b, c EMSA demonstrated more efficient binding of PPAR $\alpha$ oligonucleotides to nuclear proteins of $\mathrm{Abcb} 4^{-/-}$ mice in comparison to WT and less efficient in $\mathrm{HBs} / \mathrm{Abcb}^{-1-}$ in comparison to HBs. d Relative mRNA expression of major genes involved in beta oxidation and lipolysis, PPAR $\alpha$ and LPL, in liver of four

\section{Abcb4 knockout enhanced lipolysis in $\mathrm{HBs} / \mathrm{Abcb}^{-1-}$ mice}

Increased TAG lipolysis with increased FFA accumulation associated with PPAR $\alpha$ activation in $\mathrm{Abcb} 4^{-1-}$ mice was reported earlier [3]. In order to investigate whether the increase in $\mathrm{FFA}$-as observed in $\mathrm{HBs} / \mathrm{Abcb}^{-1-}$ mice (Fig. 1d)—was caused by increased TAG lipolysis, we performed a total lipase activity assay using total liver lysates. We found increased lipase activity in Abcb4 $4^{-1-}$ mice but no differences between HBs and HBs/Abcb4 $4^{-1-}$ mice (Fig. 5a).

Since FFAs can activate PPAR $\alpha$, which subsequently regulates the peroxisomal beta oxidation pathway of fatty acids [33], we investigated the PPAR $\alpha$ activation in our experimental setup. The transcriptional analysis demonstrated equal expression of Ppara in HBs and HBs/Abcb4 $4^{-/-}$ (Fig. 5b). Interestingly Ppar $\alpha$ expression was reduced in $\mathrm{HBs} / \mathrm{Abcb}^{-1-}$ in comparison to $\mathrm{Abcb}^{-1-}$ (Fig. 5b). EMSA indicated an increased nuclear binding activity of $\mathrm{PPAR} \alpha$ in $\mathrm{Abcb} 4^{-1-}$ mice but not in $\mathrm{HBs} / \mathrm{Abcb} 4^{-1-}$-mice (Fig. 5c). PPAR $\alpha$ activation subsequently regulates its different groups, relative to WT, normalized against $\beta$-actin (PPAR $\alpha$ ) and GAPDH (LPL) gene. Details of the primers used are listed in Table 1. The results are presented as mean \pm SEM, $n=7-10(3-50+$ 4-5\%, age 16-19 weeks) in each group performed in duplicates. $* P<$ $0.05, * * P<0.01, * * * P<0.001$. e Representative immunohistochemical analysis of LPL depicts enhanced cytoplasmic expression in Abcb4 ${ }^{-1-}$ and $\mathrm{HBs} / \mathrm{Abcb}^{-l-}$ in comparison to WT and HBs transgenic male mice. Original image magnification $\times 200$, bar $200 \mu \mathrm{m}$.

downstream targets such as LPL and adipose TAG lipase (ATGL) [34]. $L p l$ expression was significantly increased in Abcb $4^{-1-}$ and HBs/Abcb4 ${ }^{-1-}$ compared to WT (Fig. 5d). In addition, the LPL protein expression was remarkably increased in $\mathrm{HBs} / \mathrm{Abcb}^{-1-}$ compared to $\mathrm{HBs}$ mice (Fig. 5e). PPAR $\alpha$ activity is, therefore, in line with LPL expression in $\mathrm{Abcb} 4^{-1-}$-mice but not in $\mathrm{HBs} / \mathrm{Abcb}^{-1-}{ }^{-}$-mice. Apart from LPL, other lipases such as ATGL or LAL, which are also regulated by PPAR $\alpha$ [34], yielded no significant differences in expression (data not shown). Taken together, our results demonstrated an increased hepatic LPL expression in $\mathrm{HBs} / \mathrm{Abcb}^{-1-}$ mice.

\section{Abcb4 knockout activated AMPK and CREB signaling in $\mathrm{HBs} / \mathrm{Abcb4}^{-I-}$ mice}

AMPK is an energy sensor that can induce a cellular cascade for maintaining energy homeostasis [35]. AMPK was activated in $\mathrm{Abcb} 4^{-I-}$ and $\mathrm{HBs} / \mathrm{Abcb}^{-/-}$compared to WT and HBs (Fig. 6a). CREB and related proteins are downstream targets for AMPK and therefore likely involved in mediating effects of AMPK [36]. Thus, we also investigated 

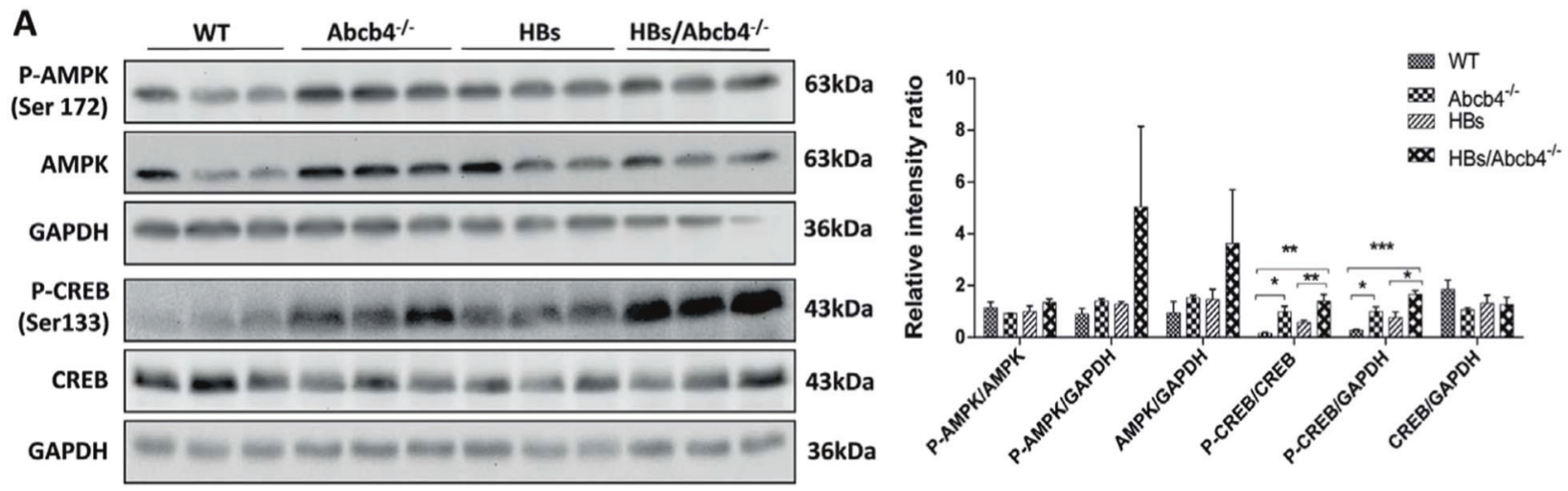

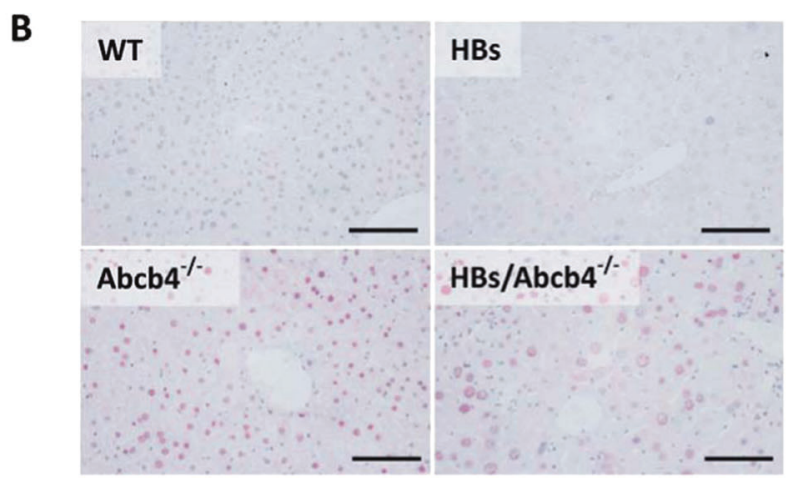

Fig. 6 Activation of AMPK and CREB in HBs/Abcb4 ${ }^{-1-}$ mice. a Western blot analysis using specific antibodies against P-AMPK, AMPK, and P-CREB were performed in male mice. Equal loading was confirmed by GAPDH analysis. b Representative immunohistochemical staining using specific antibodies against P-CREB in male mice

the hepatic activation of CREB in $\mathrm{Abcb} 4^{-1-}$ mice. Immunoblotting demonstrated the increased activation of CREB in $\mathrm{Abcb} 4^{-/-}$and $\mathrm{HBs} / \mathrm{Abcb} 4^{-/-}$compared to wild-type and HBs transgenic mice (Fig. 6a). Similarly, immunohistochemical studies with specific P-CREB antibodies confirmed the above findings (Fig. 6b). Western blot analysis and immunostaining also demonstrated the increased activation of CREB in $\mathrm{Abcb}_{4}^{-1-}$, $\mathrm{HBs}$, and $\mathrm{HBs} / \mathrm{Abcb}^{-1-}$ compared to wild type in female mice (Supplementary Fig. 3a, b). In addition, EMSA results showed increased nuclear binding of CREB in $\mathrm{HBs} / \mathrm{Abcb} 4^{-1-}$ compared to Abcb4 ${ }^{-/-}$, wild-type, and HBs transgenic mice (Fig. 6c). Hence, our data suggest that $\mathrm{Abcb} 4^{-1-}$ induced cholestatic liver injury might affect hepatic lipid metabolism by the activation of AMPK and CREB signaling in HBs transgenic mice.

\section{Bile acid treatment induced AMPK-CREB activation in HepG2 cells}

To further prove the mechanistic principle of cholestasis induced disturbances in lipid metabolism in HBs mice, HepG2 cells were used to mimic the situation in vitro. Oleic

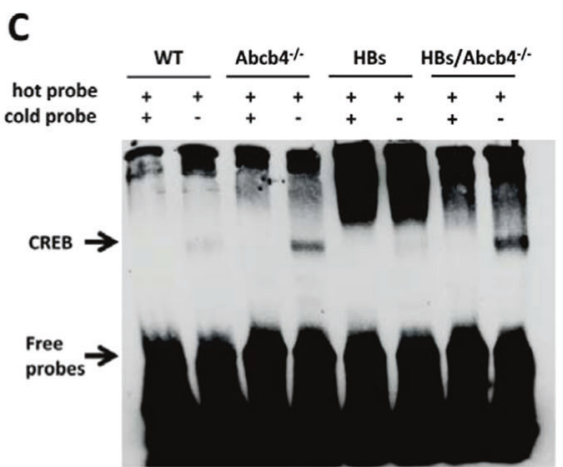

(original image magnification $\times 400$, bar $200 \mu \mathrm{m}$ ). c EMSA demonstrated more efficient binding of CREB oligonucleotides to nuclear proteins of $\mathrm{Abcb}^{-1-}$ and $\mathrm{HBs} / \mathrm{Abcb} 4^{-1-}$ mice in comparison to WT and HBs in male mice.

acid pretreatment of HepG2 cells increased intracellular LDs. The subsequent treatment with BA increased the phosphorylation of AMPK and CREB in HepG2 cells (Fig. 7a). The protein expression of FASN and PLIN2 was reduced in the BA treated group, which was concomitant with the activation of AMPK signaling by bile acid treatment (Fig. 7a). In addition, the LDs associated protein, PLIN2, was reduced remarkably in the treated group compared to vehicle (Fig. 7a). Furthermore, we simulated the in vivo situation by the treatment of HBs overexpressing HepG2 cells with BA. Central aspects like CREB activation and PLIN2 reduction were also demonstrated in this setting (Fig. S4).

To confirm that the effect of bile acid on decreased TAG synthesis and storage was dependent on AMPK-CREB signaling, HepG2 cells preloaded with oleic acid were treated with the specific AMPK inhibitor dorsomorphin in the presence and absence of BA. The activation of AMPK and also CREB by BA was blocked by dorsomorphin (Fig. 7b). Importantly, the downstream targets of AMPK, FASN, and PLIN2, were induced after treatment with the inhibitor (Fig. 7b), suggesting that AMPK activation by BA regulates genes that are involved in lipid synthesis. Our data 


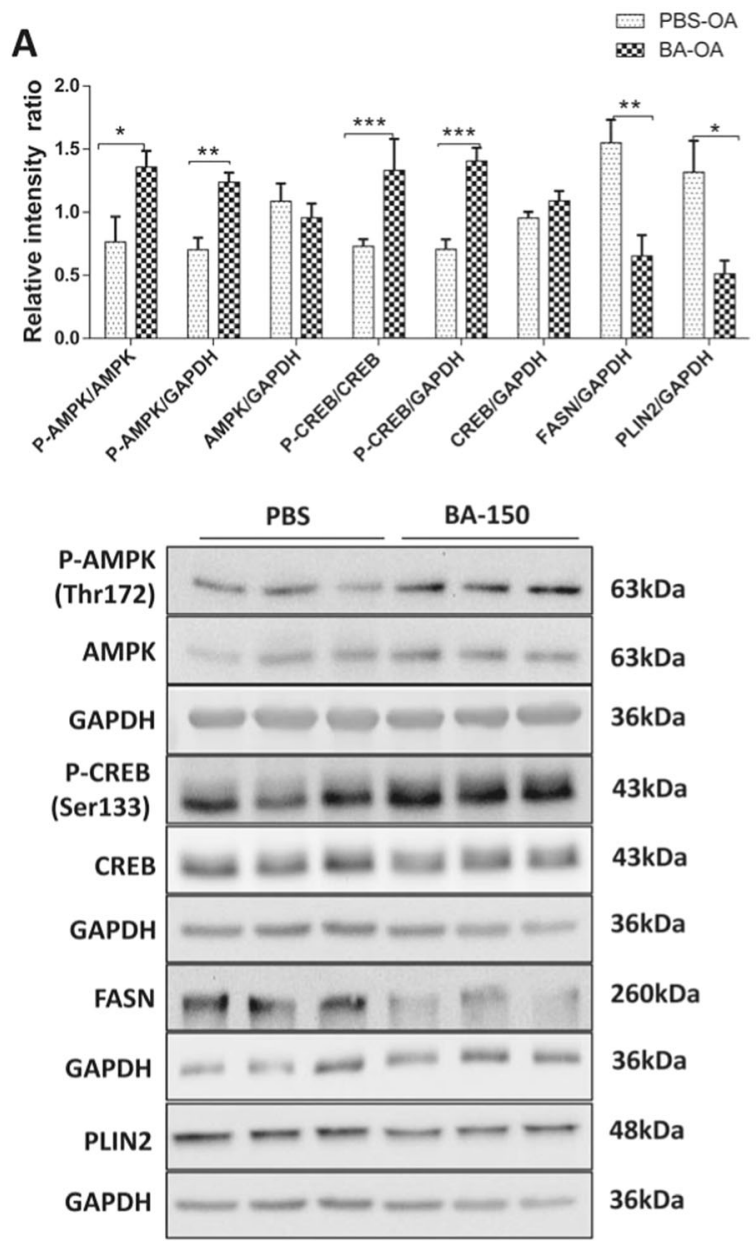

Fig. 7 In vitro bile acid treatment induced AMPK and CREB activation in HepG2 cells. a Western blot analysis of P-AMPK $(\alpha 172)$, AMPK, P-CREB, FAS, and PLIN2 protein expression levels in HepG2 cells pretreated with $250 \mu \mathrm{M}$ of oleic acid for $12 \mathrm{~h}$ followed by treatment with bile acids (cholic-deoxycholate salt) at $150 \mu \mathrm{M}$ conc. for $24 \mathrm{~h}$. GAPDH was used as a loading control. $n=3$, each experiment was repeated at least three times. $\mathbf{b}$ Western blot analysis of P-

suggest that bile acid suppresses TAG synthesis and storage in HepG2 cells via activation of the AMPK and CREB signaling pathways.

\section{Discussion}

Cholestasis in NAFLD patients is associated with more pronounced liver injury, inflammation, and disturbances in glucose and lipid metabolism contributing to the progressive course of NAFLD [37]. Clinical studies reported that primary biliary fibrosis and biliary atresia occurred in patients with HBV infection [38, 39]. Similarly, biliary diseases might even be attributed to or caused by HBV infection [39]. We have reported earlier that HBs can enhance cholestatic liver injury, fibrosis, and tumorigenesis in $A b c b 4$ knockout mice [23]. Therefore, there is an urgent

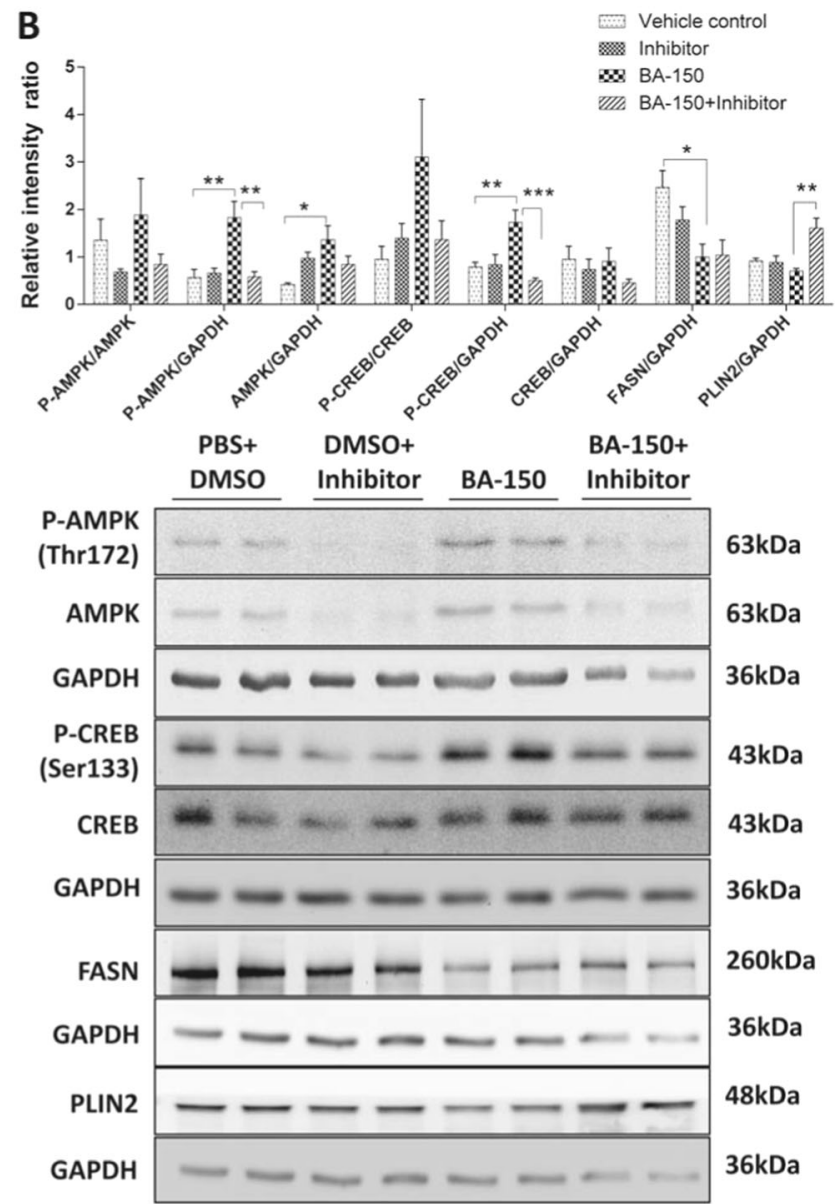

AMPK ( $\alpha 172)$, AMPK, P-CREB, FAS, PLIN2 protein expression levels in HepG2 cells pretreated with $250 \mu \mathrm{M}$ of oleic acid for $12 \mathrm{~h}$ followed by treatment with bile acids (cholic-deoxycholate salt) at 150 $\mu \mathrm{M}[30,49]$ in the presence and absence of dorsomorphin, $10 \mu \mathrm{M}$ (AMPK inhibitor) conc. for $24 \mathrm{~h}$. GAPDH was used as a loading control. $n=3$. All experiments were repeated at least three times.

need for medical correction of cholestasis at the earliest form of fatty liver diseases. With regard to chronic HBV infection, concurrent NAFLD represents a "second hit" that can aggravate the disease [6] and the metabolic syndrome is associated with severe fibrosis in $\mathrm{CVH}$ [40]. In the current study, we investigated the effect of an $A b c b 4$ knockout on hepatic lipid metabolism in HBs transgenic mice to understand the relevant biological processes with regard to disease development and progression. Our present study demonstrates reduced hepatic lipogenesis, reduced TAG synthesis, and enhanced lipid catabolism in $\mathrm{HBs} / \mathrm{Abcb}^{-1-}$ mice. The activation of AMPK-CREB pathway is suggested to be a major player regulating the changes in hepatic lipid metabolism thereby contributing significantly to the pathogenesis of cholestatic liver injury in HBs mice.

Remarkably, our study revealed a reduction of hepatic TAGs in HBs/Abcb4 $4^{-I-}$ mice (Fig. 1a-c). Serum TAGs and 
cholesterol were reduced in $\mathrm{HBs} / \mathrm{Abcb} 4^{-1-}$ mice compared to wild types (Fig. 1g, h). Cholestatic liver disease with toxic accumulation of bile components might disturb many aspects of lipid absorption and metabolism [34]. Furthermore, BA are involved in regulating their own synthesis and enterohepatic circulation, but also TAGs, cholesterol, glucose, and energy homeostasis [41]. Interestingly, we observed increased hepatic FFA levels in $\mathrm{Abcb}^{-1-}$ and HBs/Abcb4 ${ }^{-1-}$ mice (Fig. 1d). The induction of hepatic fatty acyl-CoAs and the reduction of TAG esterification and storage has already been described in Abcb4 $4^{-1-}$ mice [3]. Accordingly, our data also demonstrated a similar effect of Abcb4 ${ }^{-1-}$ on enhanced hepatic TAG levels in HBs transgenic mice (Fig. 1a-d).

FFAs have been shown to activate PPAR $\alpha$ [42]. The functional nuclear binding of $\operatorname{PPAR} \alpha$ was increased in our Abcb4 $4^{-1-}$ mice but nearly no differences were found between $\mathrm{HBs}$ and $\mathrm{HBs} / \mathrm{Abcb} 4^{-1-}$ (Fig. 5c). PPAR $\alpha$ itself can regulate all sequential steps of TAG catabolism including the regulation of lipases, including LPL [43]. The current data do not provide an explanation for the discrepancy between PPAR $\alpha$ and LPL regulation. Nevertheless, PPAR $\alpha$ target genes, including lipases, were found to be regulated in $\mathrm{HBs} / \mathrm{Abcb} 4^{-1-}$ mice (Fig. $5 \mathrm{~d}$, e). As the liver specific knockout of LPL has no impact on hepatic TG levels [44], it is questionable if the increased expression of LPL, both on transcriptional and translational level in HBs/ Abcb4 $4^{-1-}$ mice in comparison to HBs and WT, might be causal for the reduction of TAGs.

In normal physiological states, FFA serve as a preferential substrate for TAG esterification and storage. Herein, higher levels of FFA, in parallel with low levels of TAGs in $\mathrm{Abcb}^{-1-}$ and $\mathrm{HBs} / \mathrm{Abcb} 4^{-1-}$ indicate either a suppression of the enzyme machinery involved in TAG synthesis or an enhancement of lipolytic activity. The genes and proteins regulating the enzymes involved in TAG synthesis might also contribute to the reduced TAG levels in $\mathrm{HBs} / \mathrm{Abcb}^{-1-}$ mice (Fig. $4 \mathrm{a}-\mathrm{g}$ ). TAG biosynthesis from glycerol-3-phosphate is catalyzed by a number of protein isoforms of the glycerol phosphate acyltransferase (GPAT), acylglycerolphosphate acyltransferase (AGPAT), and lipin (phosphatidate phosphatase) families, that appear to catalyze similar biochemical reactions [45]. Notably, AGPAT1 and GPAT1 were significantly reduced in $\mathrm{HBs} / \mathrm{Abcb} 4^{-1-}$ mice (Fig. 4d, e). The protein expression of DGAT1 and the transcriptional level of DGAT2 appeared remarkably decreased in $\mathrm{HBs} / \mathrm{Abcb}^{-1-}$ (Fig. 4c, f). The reduced expression of AGPAT1, GPAT1, MGAT1, and DGAT2 suggests that FFAs could not be utilized for TAG synthesis in $\mathrm{Abcb} 4^{-1-}$ and $\mathrm{HBs} / \mathrm{Abcb} 4^{-1-}$ mice.

Several studies indicated the beneficial effects of lipid storage and loss of TAG storage capacity being critically linked to lipotoxicity, which has been shown to exacerbate liver injury [46]. Therefore, increased FFA levels in parallel with suppression of TAG synthesis and storage along with enhanced lipolysis pathways in $\mathrm{HBs} / \mathrm{Abcb}^{-/-}$mice might also contribute to the acceleration of liver injury [23].

The activation of AMPK inhibits hepatic fatty acid synthesis and promotes fatty acid oxidation via phosphorylation and inactivation of ACC1 [19] and the phosphorylation of specific transcription factors such as SREBP1c by AMPK results in a reduced expression of lipogenic and gluconeogenic enzymes [47]. Our data clearly show an increased activation of AMPK in $\mathrm{Abcb} 4^{-1-}$ and $\mathrm{HBs} / \mathrm{Abcb} 4^{-1-}$ mice (Fig. 6a). Alongside the increased activation of AMPK, we demonstrate a decrease in genes responsible for lipogenesis, i.e. Srebplc, Fasn, Accl Scd1, Hmgcs1, and Ppary in HBs/ Abcb4 ${ }^{-1-}$ mice (Fig. 2a-f). Also genes which are involved in the uptake and secretion of lipids such as $C d 36, A p o E$, and Pctp were downregulated in $\mathrm{HBs} / \mathrm{Abcb} 4^{-1-}$ mice. Although Hmgcsl expression decreased in $\mathrm{HBs} / \mathrm{Abcb} 4^{-1-}$ mice compared to $\mathrm{HBs}$ (Fig. 2e), the hepatic cholesterol level remained constant (Fig. 1e). Nevertheless, serum cholesterol was significantly decreased in $\mathrm{HBs} / \mathrm{Abcb} 4^{-1-}$ mice compared to wild-type mice (Fig. 1h). Cholesterol absorption is dependent on micellar solubilization together with BA and fatty acids [41]. Thus, cholesterol uptake might be affected in $\mathrm{HBs} / \mathrm{Abcb} 4^{-/-}$mice (Fig. 1h) as elevated plasma bile acid levels are a characteristic hallmark in $\mathrm{Abcb}^{-1-}$ mice [48] as well as in $\mathrm{HBs} / \mathrm{Abcb} 4^{-1-}$ mice [23].

Previous studies reported that the AMPK-mediated phosphorylation of the LD-associated protein PLIN2 is essential for subsequent selective degradation and triggering of lipolysis [22], suggesting an interplay between AMPK and PLIN2 in regulating intracellular TAG storage. PLIN2, being the major LD-associated protein, protects and stabilizes LDs, provides a "shielding effect" and modulates lipase's accessibility to TAGs [22]. Furthermore, the reduction of PLIN2 expression by antisense oligonucleotide treatment led to decreased hepatic lipid accumulation [49]. However, the association of Abcb4 mediated reduction of TAGs and PLIN2 has not been reported so far. Here our study showed a reduction of PLIN2 both in vivo and in vitro (Figs. 3a-c and 7a, b) suggesting a role of cholestasis mediated regulation on PLIN2 expression.

Previous reports suggested that CREB could be induced by AMPK [50]. These observations, along with scanning of peptide sequences for AMPK recognition motifs, led to the hypothesis that CREB may influence lipid homeostasis together with AMPK [36]. Notably, CREB was activated in $\mathrm{HBs} / \mathrm{Abcb}^{-1-}$ in comparison to $\mathrm{Abcb} 4^{-1-}$ and $\mathrm{HBs}$ mice (Fig. 6a, b). In addition to its role in promoting fatty acid breakdown, CREB also appears to block the expression of lipogenic pathways [20]. Intriguingly, our study also shows a decreased expression of PPAR $\gamma$ in $\mathrm{HBs} / \mathrm{Abcb} 4^{-1-}$ mice 
(Fig. 2f). Mice deficient in CREB activity have a fatty liver phenotype and display an elevated expression of the nuclear hormone receptor PPAR- $\gamma$, a key regulator of lipogenic genes [20]. Similarly, our cell culture models of cholestasis demonstrated increased activation of AMPK and CREB along with downregulation of FASN and PLIN2 in HepG2 cells, emphasizing the possible role of bile acid in lipid metabolism during cholestatic liver injury (Fig. 7a, b). Finally, AMPK inhibition reversed this effect, which underlines a mechanistic association.

In summary, the hepatic lipid metabolism in HBs mice was altered by concomitant cholestasis induced via $A b c b 4$ transporter knockout. AMPK and CREB signaling could mediate this process. The results of the current study may trigger the development of novel therapeutic strategies as NASH is a crucial factor able to aggravate chronic liver disease in HBV infected patients [6]. In conclusion, a pharmacological modulation of AMPK and CREB signaling might be a promising therapeutic concept for the treatment of fatty liver diseases.

Acknowledgements We thank Heike Muller and Annette Tschuschner for excellent technical assistance. This work was supported by grants from DAAD (\#91606935 to KI), von-Behring-Roentgen Foundation (\#58-0005 to ER and \#60-0002 to MR), and University Medical Center Giessen and Marburg (UKGM) (\#21_2013 GI to ER and \#7_2014 GI to MR). Open Access Funding provided by Projekt DEAL.

\section{Compliance with ethical standards}

Conflict of interest The authors declare that they have no conflict of interest.

Publisher's note Springer Nature remains neutral with regard to jurisdictional claims in published maps and institutional affiliations.

Open Access This article is licensed under a Creative Commons Attribution 4.0 International License, which permits use, sharing, adaptation, distribution and reproduction in any medium or format, as long as you give appropriate credit to the original author(s) and the source, provide a link to the Creative Commons license, and indicate if changes were made. The images or other third party material in this article are included in the article's Creative Commons license, unless indicated otherwise in a credit line to the material. If material is not included in the article's Creative Commons license and your intended use is not permitted by statutory regulation or exceeds the permitted use, you will need to obtain permission directly from the copyright holder. To view a copy of this license, visit http://creativecommons. org/licenses/by/4.0/.

\section{References}

1. Trauner M, Fickert $P$, Stauber RE. Inflammation-induced cholestasis. J Gastroenterol Hepatol. 1999;14:946-59.

2. Reichert MC, Lammert F. ABCB4 gene aberrations in human liver disease: an evolving spectrum. Semin Liver Dis. 2018;38:299-307.
3. Moustafa T, Fickert P, Magnes C, Guelly C, Thueringer A, Frank $\mathrm{S}$, et al. Alterations in lipid metabolism mediate inflammation, fibrosis, and proliferation in a mouse model of chronic cholestatic liver injury. Gastroenterology. 2012;142:140-51.

4. Ikenaga N, Liu SB, Sverdlov DY, Yoshida S, Nasser I, Ke Q, et al. A new Mdr2(-/-) mouse model of sclerosing cholangitis with rapid fibrosis progression, early-onset portal hypertension, and liver cancer. Am J Pathol. 2015;185:325-34.

5. Mendes LC, Stucchi RS, Vigani AG. Diagnosis and staging of fibrosis in patients with chronic hepatitis C: comparison and critical overview of current strategies. Hepat Med. 2018;10:13-22.

6. Choi HSJ, Brouwer WP, Zanjir WMR, Man RA, de, Feld JJ, Hansen BE, et al. Nonalcoholic steatohepatitis is associated with liver-related outcomes and all-cause mortality in chronic hepatitis B. Hepatology. 2020;71:539-48.

7. Chisari FV, Filippi P, Buras J, McLachlan A, Popper H, Pinkert $\mathrm{CA}$, et al. Structural and pathological effects of synthesis of hepatitis B virus large envelope polypeptide in transgenic mice. Proc Natl Acad Sci USA. 1987;84:6909-13.

8. Chung Y-L, Wu M-L. The role of promyelocytic leukemia protein in steatosis-associated hepatic tumors related to chronic hepatitis B virus infection. Transl Oncol. 2018;11:743-54.

9. Chisari FV, Klopchin K, Moriyama T, Pasquinelli C, Dunsford HA, Sell S, et al. Molecular pathogenesis of hepatocellular carcinoma in hepatitis B virus transgenic mice. Cell. 1989;59:1145-56.

10. Churin Y, Roderfeld M, Stiefel J, Würger T, Schröder D, Matono $\mathrm{T}$, et al. Pathological impact of hepatitis B virus surface proteins on the liver is associated with the host genetic background. PLoS ONE. 2014;9:e90608.

11. Montalbano R, Honrath B, Wissniowski TT, Elxnat M, Roth S, Ocker M, et al. Exogenous hepatitis B virus envelope proteins induce endoplasmic reticulum stress: involvement of cannabinoid axis in liver cancer cells. Oncotarget. 2016;7:20312-23.

12. Bondini S, Kallman J, Wheeler A, Prakash S, Gramlich T, Jondle $\mathrm{DM}$, et al. Impact of non-alcoholic fatty liver disease on chronic hepatitis B. Liver Int. 2007;27:607-11.

13. Liang J, Liu F, Wang F, Han T, Jing L, Ma Z, et al. A noninvasive score model for prediction of NASH in patients with chronic hepatitis B and nonalcoholic fatty liver disease. Biomed Res Int. 2017;2017:8793278.

14. Roeb E, Geier A. Nonalcoholic steatohepatitis (NASH)—current treatment recommendations and future developments. Z Gastroenterol. 2019;57:508-17.

15. Alwahsh SM, Gebhardt R. Dietary fructose as a risk factor for non-alcoholic fatty liver disease (NAFLD). Arch Toxicol. 2017;91:1545-63.

16. Brandt A, Hernández-Arriaga A, Kehm R, Sánchez V, Jin CJ, Nier A, et al. Metformin attenuates the onset of non-alcoholic fatty liver disease and affects intestinal microbiota and barrier in small intestine. Sci Rep. 2019;9:6668.

17. Mahli A, Saugspier M, Koch A, Sommer J, Dietrich P, Lee S, et al. ERK activation and autophagy impairment are central mediators of irinotecan-induced steatohepatitis. Gut. 2018;67:746-56.

18. Towler MC, Hardie DG. AMP-activated protein kinase in metabolic control and insulin signaling. Circ Res. 2007;100:328-41.

19. Wang Q, Liu S, Zhai A, Zhang B, Tian G. AMPK-mediated regulation of lipid metabolism by phosphorylation. Biol Pharm Bull. 2018;41:985-93.

20. Herzig S, Hedrick S, Morantte I, Koo S-H, Galimi F, Montminy M. CREB controls hepatic lipid metabolism through nuclear hormone receptor PPAR-gamma. Nature. 2003;426:190-3.

21. Kimmel AR, Brasaemle DL, McAndrews-Hill M, Sztalryd C, Londos C. Adoption of PERILIPIN as a unifying nomenclature for the mammalian PAT-family of intracellular lipid storage droplet proteins. J Lipid Res. 2010;51:468-71. 
22. Kaushik S, Cuervo AM. AMPK-dependent phosphorylation of lipid droplet protein PLIN2 triggers its degradation by CMA. Autophagy. 2016;12:432-8.

23. Zahner D, Glimm H, Matono T, Churin Y, Herebian D, Mayatepek E, et al. Hepatitis B virus surface proteins accelerate cholestatic injury and tumor progression in Abcb4-knockout mice. Oncotarget. 2017;8:52560-70.

24. Roderfeld M, Rath T, Lammert F, Dierkes C, Graf J, Roeb E. Innovative immunohistochemistry identifies MMP-9 expressing macrophages at the invasive front of murine HCC. World $\mathbf{J}$ Hepatol. 2010;2:175-9.

25. Roderfeld M, Rath T, Voswinckel R, Dierkes C, Dietrich H, Zahner $\mathrm{D}$, et al. Bone marrow transplantation demonstrates medullar origin of CD34+ fibrocytes and ameliorates hepatic fibrosis in Abcb4-/- mice. Hepatology. 2010;51:267-76.

26. Roderfeld M, Padem S, Lichtenberger J, Quack T, Weiskirchen R, Longerich $\mathrm{T}$, et al. Schistosoma mansoni egg-secreted antigens activate hepatocellular carcinoma-associated transcription factors c-Jun and STAT3 in hamster and human hepatocytes. Hepatology. 2018. https://doi.org/10.1002/hep.30192.

27. Livak KJ, Schmittgen TD. Analysis of relative gene expression data using real-time quantitative PCR and the 2(-delta delta $\mathrm{C}(\mathrm{T})$ ) method. Methods. 2001;25:402-8.

28. Anderson AA, Altafaj X, Zheng Z, Wang Z-M, Delbono O, Ronjat M, et al. The junctional SR protein JP-45 affects the functional expression of the voltage-dependent $\mathrm{Ca} 2+$ channel Cav1.1. J Cell Sci. 2006;119:2145-55.

29. Laggai S, Simon Y, Ranssweiler T, Kiemer AK, Kessler SM. Rapid chromatographic method to decipher distinct alterations in lipid classes in NAFLD/NASH. World J Hepatol. 2013;5:558-67.

30. Krüger S, Bürmann L, Morlock GE. Comparison and characterization of soybean and sunflower lecithins used for chocolate production by high-performance thin-layer chromatography with fluorescence detection and electrospray mass spectrometry. J Agric Food Chem. 2015;63:2893-901.

31. Nassal M. The arginine-rich domain of the hepatitis B virus core protein is required for pregenome encapsidation and productive viral positive-strand DNA synthesis but not for virus assembly. J Virol. 1992;66:4107-16.

32. Tsai T-H, Chen E, Li L, Saha P, Lee H-J, Huang L-S, et al. The constitutive lipid droplet protein PLIN2 regulates autophagy in liver. Autophagy. 2017;13:1130-44.

33. Reddy JK, Hashimoto T. Peroxisomal beta-oxidation and peroxisome proliferator-activated receptor alpha: an adaptive metabolic system. Annu Rev Nutr. 2001;21:193-230.

34. Deng T, Shan S, Li P-P, Shen Z-F, Lu X-P, Cheng J, et al. Peroxisome proliferator-activated receptor-gamma transcriptionally up-regulates hormone-sensitive lipase via the involvement of specificity protein-1. Endocrinology. 2006;147:875-84.

35. Heidrich F, Schotola H, Popov AF, Sohns C, Schuenemann J, Friedrich M, et al. AMPK-activated protein kinase and its role in energy metabolism of the heart. Curr Cardiol Rev. 2010;6:337-42.
36. Thomson DM, Herway ST, Fillmore N, Kim H, Brown JD, Barrow JR, et al. AMP-activated protein kinase phosphorylates transcription factors of the CREB family. J Appl Physiol. 2008;104:429-38.

37. Shipovskaya AA, Dudanova OP. Intrahepatic cholestasis in nonalcoholic fatty liver disease. Ter Arkh. 2018;90:69-74.

38. Rigopoulou EI, Zachou K, Gatselis NK, Papadamou G, Koukoulis GK, Dalekos GN. Primary biliary cirrhosis in HBV and HCV patients: clinical characteristics and outcome. World J Hepatol. 2013;5:577-83.

39. Javaid A, Poongkunran M, Allard FD, Kyaw W, Maung HH, Lau D. Subtle presentation of active primary biliary cirrhosis in chronic hepatitis B: a case report. Gastroenterol Rep. 2017;5:157-60.

40. Tsochatzis E, Papatheodoridis GV, Manesis EK, Kafiri G, Tiniakos DG, Archimandritis AJ. Metabolic syndrome is associated with severe fibrosis in chronic viral hepatitis and nonalcoholic steatohepatitis. Aliment Pharmacol Ther. 2008;27: 80-9.

41. Aguiar Vallim TQ, de, Tarling EJ, Edwards PA. Pleiotropic roles of bile acids in metabolism. Cell Metab. 2013;17:657-69.

42. Montagner A, Polizzi A, Fouché E, Ducheix S, Lippi Y, Lasserre $F$, et al. Liver PPAR $\alpha$ is crucial for whole-body fatty acid homeostasis and is protective against NAFLD. Gut. 2016;65:1202-14.

43. Rakhshandehroo M, Sanderson LM, Matilainen M, Stienstra R, Carlberg C, Groot PJde, et al. Comprehensive analysis of PPARalpha-dependent regulation of hepatic lipid metabolism by expression profiling. PPAR Res. 2007;2007:26839.

44. Liu G, Xu J-N, Liu D, Ding Q, Liu M-N, Chen R, et al. Regulation of plasma lipid homeostasis by hepatic lipoprotein lipase in adult mice. J Lipid Res. 2016;57:1155-61.

45. Takeuchi K, Reue K. Biochemistry, physiology, and genetics of GPAT, AGPAT, and lipin enzymes in triglyceride synthesis. Am J Physiol Endocrinol Metab. 2009;296:1195-209.

46. Yamaguchi K, Yang L, McCall S, Huang J, Yu XX, Pandey SK, et al. Inhibiting triglyceride synthesis improves hepatic steatosis but exacerbates liver damage and fibrosis in obese mice with nonalcoholic steatohepatitis. Hepatology. 2007;45:1366-74.

47. Hardie DG. AMP-activated protein kinase as a drug target. Annu Rev Pharmacol Toxicol. 2007;47:185-210.

48. Cai S-Y, Mennone A, Soroka CJ, Boyer JL. Altered expression and function of canalicular transporters during early development of cholestatic liver injury in Abcb4-deficient mice. Am J Physiol Gastrointest Liver Physiol. 2014;306:670-6.

49. Imai Y, Boyle S, Varela GM, Caron E, Yin X, Dhir R, et al. Effects of perilipin 2 antisense oligonucleotide treatment on hepatic lipid metabolism and gene expression. Physiol Genomics. 2012;44:1125-31.

50. Garcia D, Shaw RJ. AMPK: mechanisms of cellular energy sensing and restoration of metabolic balance. Mol Cell. 2017;66:789-800. 